\title{
Disponibilidade hídrica na microrregião do alto Pantanal Mato- Grossense, Brasil
}

O presente estudo teve como objetivo elaborar curvas de permanência para estimar a disponibilidade hídrica na Microrregião do Alto Pantanal Mato-grossense. A referida microrregião é formada pelos municípios Barão de Melgaço, Cáceres, Curvelândia e Poconé, estando inserida na Região Hidrográfica do Paraguai, sendo drenada por importantes cursos d'água, tais como o Rio Paraguai, Rio Cuiabá e Rio São Lourenço, dentre outros tributários. Os dados utilizados foram referentes às séries históricas de vazões diárias durante um período superior a 30 anos, variando entre os anos 1960 e 2019, e que pertencem ao banco de dados da Agência Nacional de Águas e Saneamento Básico (ANA), Sistema Nacional de Informações sobre Recursos Hídricos (SNIRH). Também, foram consultadas as bases cartográficas da região para obter os arquivos com formato para dados geoespaciais em forma de vetor, disponíveis no portal do Instituto (SNIRH). Também, foram consultadas as bases cartográficas da região para obter os arquivos com formato para dados geoespaciais em forma de vetor, disponíveis no portal do Instituto
Brasileiro de Geografia e Estatística (IBGE). Os dados referentes às vazões foram organizados em planilhas Excel e os procedimentos gráficos e analíticos para a construção das curvas foram realizados com auxílio do programa R. Concluiu-se que as curvas de permanência elaboradas nesta pesquisa foram adequadas, precisas e confiáveis para avaliar a disponibilidade hídrica do principais rios na microrregião do Alto Pantanal Mato-grossense, bem como estimar a vazão, em função da frequência de duração. Ao longo da série histórica analisada, as estações que apresentaram a maior e a menor vazão de permanência foram, respectivamente, a Pousada Taiamã (Rio Cuiabá) e Perto de Poconé (Rio Bento Gomes). Ressalta-se que a disponibilidade hídrica mais estável foi observada na estação Pousada Taiamã. A metodologia aplicada apresentou-se como excelente ferramenta para verificar os limites de vazão diária e diagnosticar 0 estado dos cursos d'água na região, em relação ao uso e ocupação do solo, auxiliando no planejamento e distribuição racional dos recursos hídricos.

Palavras-chave: Bacia Hidrográfica; Vazão de referência; Curvas de permanência; Recursos hídricos.

\section{Water availability in the micro-region of the high Pantanal Mato- Grossense, Brazil}

\begin{abstract}
The present study aimed to develop permanence curves to estimate water availability in the High Pantanal Mato-grossense region. The micro-region is formed by the municipalities Barão de Melgaço, Cáceres, Curvelândia and Poconé, being inserted in the Hydrographic Region of Paraguay, being drained by important watercourses, such as the Paraguay River, Cuiabá River and São Lourenço River, among other tributaries. The data used were related to the historical series of daily flows over a period of more than 30 years, varying between the 1960 s and 2019 , and which belong to the database of the Water and Sanitation Agency (ANA), National Water Resources Information System (SNIRH). Also, the cartographic bases of the region were consulted to obtain the files with format for geospatial data in vector form, available on the portal of the Brazilian Institute of Geography and Statistics (IBGE). The data referring to flows were organized to obtain the files with format for geospatial data in vector form, available on the portal of the Brazilian Institute of Geography and Statistics (IBGE). The data referring to flows were organized in Excel spreadsheets and the graphic and analytical procedures for the construction of the curves were performed with the aid of $R$ program. It was concluded that the permanence curves elaborated in this research were adequate, accurate and reliable to evaluate the water availability of the main rivers in the Upper Pantanal micro-region of Mato Grosso, as well as to estimate the flow, according to the frequency of duration. Throughout the historical series analyzed, the stations that had the highest and lowest flow rate were, respectively, Pousada Taiamã (Cuiaba River) and Perto de Poconé (Bento Gomes River). It should be noted that the most stable water availability was observed at the Pousada Taiamã station. The applied methodology was
\end{abstract}

Keywords: Hydrographic basin; Reference flow; Permanence curves; Water resources.

Topic: Engenharia de Recursos Hídricos

Reviewed anonymously in the process of blind peer.
Received: 03/04/2021

Approved: 26/04/2021
Pedro Hurtado de Mendoza Borges (iD) Universidade Federal de Mato Grosso, Brasil http://lattes.cnpq.br/0310556104378957 http://orcid.org/0000-0001-7603-8775

pborges@ufmt.br

Zaira Morais dos Santos Hurtado de Mendoza (ic

Universidade Federal de Mato Grosso, Brasil http://lattes.cnpq.br/7829408545924908 http://orcid.org/0000-0002-0930-7928

zaira@ufmt.br

Pedro Hurtado de Mendoza Morais (it

Universidade Federal de Mato Grosso, Brasil

http://lattes.cnpq.br/9517941254638374

http://orcid.org/0000-0003-2431-9262

pedromorais08@hotmail.com
Referencing this:

BORGES, P. H. M.; MENDOZA, Z. M. S. H.; MORAIS, P. H. M. Disponibilidade hídrica na microrregião do alto Pantanal MatoGrossense, Brasil. Revista Ibero Americana de Ciências Ambientais, v.12, n.4, p.276-287, 2021. DOI: http://doi.org/10.6008/CBPC21796858.2021.004.0023 


\section{INTRODUÇÃO}

O Pantanal constitui uma das maiores e mais diversificadas áreas alagáveis do planeta, decorrentes dos períodos de alta precipitação em combinação com uma paisagem relativamente plana, que dificulta a drenagem periódica do excesso de água (JUNK et al., 1999). As águas dos rios fluem do planalto em direção à depressão do Pantanal, e, em seus fluxos, os rios movem-se lentamente quando atingem as terras planas da planície pantaneira, inundando periodicamente as áreas marginais (ALHO, 2011). O referido autor relata que, esses grandes rios são moldados em grande parte pelo tipo de solo, taxa de fluxo de água, níveis de oxigênio dissolvido, cargas de nutrientes, temperatura e tipo do leito do rio.

No Brasil, ele é um ecossistema de área úmida com grande complexidade hidrológica, perfazendo uma área de aproximadamente $150000 \mathrm{~km}^{2}$, localizado predominantemente nos estados de Mato Grosso do Sul, denominada de Microrregião do Baixo Pantanal e também em Mato Grosso que nesse caso, recebe o nome de Microrregião do Alto Pantanal, pertencendo a maior área ao Baixo Pantanal (SILVA, 2000; SILVA et al., 2004; JUNK et al., 2005; FANTIN-CRUZ et al., 2008; GONÇALVES et al., 2011; PARANHOS FILHO et al., 2014; NOVAIS et al., 2016). Conforme esses autores, a Microrregião do Alto Pantanal tem sido alvo de atividades antrópicas intensas, o que tem causado assoreamento das margens dos rios e contaminação dos corpos hídricos, em especial com metais pesados como o mercúrio.

Dentro do cenário mundial e nacional, o pantanal foi declarado como patrimônio da humanidade e Reserva da Biosfera, a partir do ano 2000, pela Organização das Nações Unidas para Educação, Ciência e Cultura - UNESCO (FERREIRA, 2013). Nesse contexto, a Microrregião do Alto Pantanal Mato-grossense apresenta-se como uma área de importância socioambiental e econômica, com crescente demanda para as atividades aquícolas sustentáveis (CURVO et al., 2020). Esse aspecto, justifica a relevância de analisar e monitorar as condições hídricas na região pantaneira, como por exemplo, a estimativa dos níveis adequados dos cursos d'água e sua propensão às enchentes ou estiagens, visando auxiliar o planejamento e gestão dos recursos naturais dessa área, contribuindo com a conservação do bioma.

Para avaliar a disponibilidade hídrica dos rios principais e tributários, diversos autores têm utilizado como principal ferramenta a elaboração das curvas de permanência (TUCCI et al., 2006; CRUZ et al., 2008; PINHEIRO et al., 2008; PRUSKI et al., 2011; COSTA et al., 2012; CALMON et al., 2016; MAJER, 2017; BELLETTINI, 2019; OLIVEIRA et al., 2020; ROLIM et al., 2020). Esses trabalhos evidenciaram a elevada eficiência das referidas curvas e sua utilidade para estimar a frequência e a probabilidade de ocorrer vazões extremas na rede de drenagem de bacias hidrográficas. Além disso, essas curvas permitem conhecer sobre o regime do rio e as vazões correspondentes dos cursos d'água, para a geração de energia e outorga de direito de uso de recursos hídricos, fornecendo subsídios e recomendações aos órgãos competentes quanto à necessidade de água.

Com base na literatura consultada, este estudo fundamenta-se na hipótese de que as referidas curvas podem servir como subsídio para fornecer os critérios necessários em relação à disponibilidade hídrica em bacias, auxiliando a tomada de decisões para atender as demandas e preservar o meio ambiente. Essa 
problemática motivou a realização da presente pesquisa, que teve como objetivo elaborar curvas de permanência para estimar a disponibilidade hídrica na Microrregião do Alto Pantanal Mato-grossense.

\section{MATERIAIS E MÉTODOS}

Para este estudo foi selecionada a Microrregião do Alto Pantanal pertencente à Mesorregião CentroSul Mato-Grossense, Brasil (Figura 1). A referida microrregião é formada pelos municípios Barão de Melgaço, Cáceres, Curvelândia e Poconé, tendo como sede o município de Cáceres. Essa zona geográfica está inserida na Região Hidrográfica do Paraguai, drenada por importantes cursos d'água, tais como o Rio Paraguai, Rio Cuiabá e Rio São Lourenço, dentre outros tributários (ANA, 2020). A região apresenta clima tropical com inverno seco, classificado como Aw (PEEL et al., 2007; ALVARES et al., 2013). A temperatura média anual desse território varia entre $24{ }^{\circ} \mathrm{C}$ e $26,5^{\circ} \mathrm{C}$ com pluviosidade média anual oscilando de $1370 \mathrm{~mm}$ a $1500 \mathrm{~mm}$ (INMET, 2020).

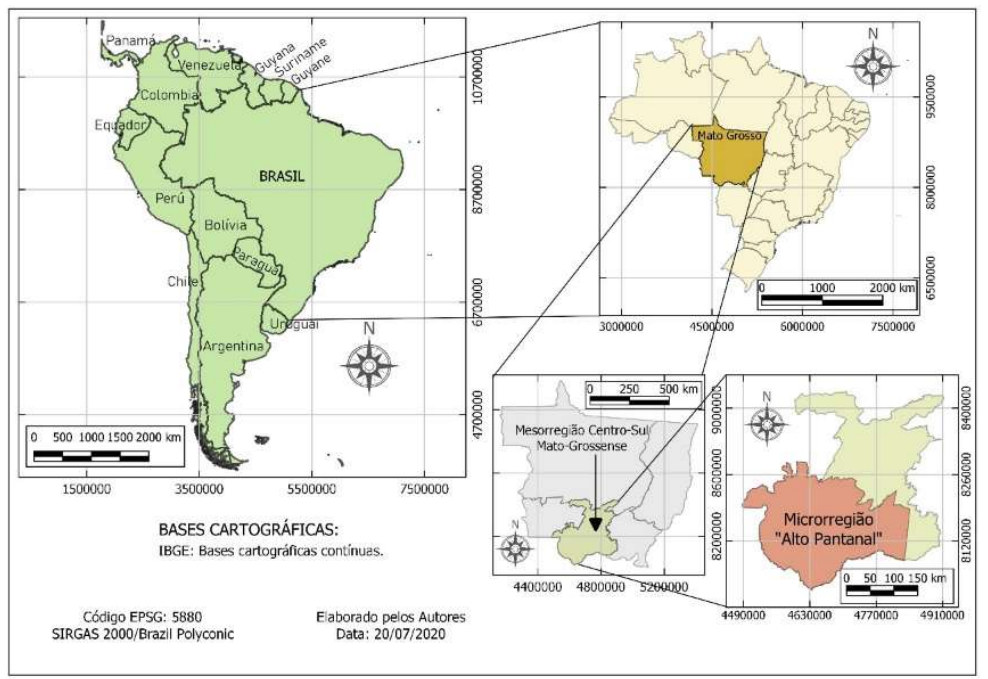

Figura 1: Localização da Microrregião do Alto Pantanal - Mato Grosso, Brasil, América do Sul.

Os dados utilizados foram referentes às séries históricas de vazões diárias coletadas nas diversas estações fluviométricas distribuídas na região, disponíveis no Portal HidroWeb do Sistema Nacional de Informações sobre Recursos Hídricos (SNIRH). Inicialmente, verificou-se que do total de 20 estações fluviométricas, apenas 11 encontraram-se ativas, cujas principais informações constam na Tabela 1. Nessa Tabela incluíram-se as coordenadas métricas na projeção Policônica, Datum SIRGAS 2000. O uso do sistema de coordenadas projetadas teve como principal finalidade, facilitar a comparação das áreas de influência e das distâncias entre os postos fluviométricos, bem como do comprimento dos cursos d'água. Além disso, o estado de Mato Grosso abrange três fusos no sistema de coordenadas planas UTM (Universal Transversa de Mercator), o que limitou a sua aplicação.

Tabela 1: Principais informações das estações fluviométricas localizadas na microrregião Alto Pantanal de Mato Grosso.

\begin{tabular}{|c|c|c|c|c|c|c|}
\hline \multirow[b]{2}{*}{ Município } & \multirow[b]{2}{*}{ Código } & \multirow[b]{2}{*}{ Nome } & \multirow[b]{2}{*}{ Rio } & \multirow{2}{*}{$\begin{array}{l}\text { Área de drenagem } \\
\left(\mathrm{km}^{2}\right)\end{array}$} & \multicolumn{2}{|l|}{ Coordenadas } \\
\hline & & & & & $\begin{array}{l}\text { Latitude* } \\
\left({ }^{\circ}\right) \text { e }(m)\end{array}$ & $\begin{array}{l}\text { Longitude* } \\
\left({ }^{\circ}\right) \text { e }(\mathrm{m})\end{array}$ \\
\hline \multirow{3}{*}{ Barão de Melgaço } & \multirow{2}{*}{66280000} & \multirow{2}{*}{ Barão de Melgaço } & \multirow{2}{*}{ Cuiabá } & \multirow{2}{*}{28900} & $-16,19277778$ & $-55,96694444$ \\
\hline & & & & & 8208017,26 & 4789675,57 \\
\hline & 66370000 & Ilha Camargo & Cuiabá & 39000 & $-17,05638889$ & $-56,58055556$ \\
\hline
\end{tabular}




\begin{tabular}{|c|c|c|c|c|c|c|}
\hline & & & & & 8111637,79 & 4725297,70 \\
\hline & \multirow{2}{*}{66470000} & \multirow{2}{*}{ São José do Boriréu } & \multirow{2}{*}{ São Lourenço } & \multirow{2}{*}{24100} & $-16,92527778$ & $-56,22361111$ \\
\hline & & & & & 8126624,12 & 4763128,33 \\
\hline & \multirow{2}{*}{66650000} & \multirow{2}{*}{ São José do Piquirí } & \multirow{2}{*}{ Piquirí } & \multirow{2}{*}{30000} & $-17,29166667$ & $-56,38722222$ \\
\hline & & & & & 8085842,24 & 4746197,63 \\
\hline \multirow{8}{*}{ Poconé } & \multirow{2}{*}{66340000} & \multirow{2}{*}{ Porto Cercado } & \multirow{2}{*}{ Cuiabá } & \multirow{2}{*}{36900} & $-16,51194444$ & $-56,37555556$ \\
\hline & & & & & 8172210,07 & 4746397,26 \\
\hline & \multirow{2}{*}{66360000} & \multirow{2}{*}{ São João } & \multirow{2}{*}{ Cuiabá } & \multirow{2}{*}{38500} & $-16,94444444$ & $-56,63277778$ \\
\hline & & & & & 8123963,34 & 4719572,38 \\
\hline & \multirow{2}{*}{66710000} & \multirow{2}{*}{ Pousada Taiamã } & \multirow{2}{*}{ Cuiabá } & \multirow{2}{*}{95200} & $-17,36555556$ & $-56,77472222$ \\
\hline & & & & & 8077105,19 & 4705120,46 \\
\hline & \multirow{2}{*}{66110000} & \multirow{2}{*}{ Perto de Poconé } & \multirow{2}{*}{ Bento Gomes } & \multirow{2}{*}{2910} & $-16,31500000$ & $-56,54222222$ \\
\hline & & & & & 8193805,66 & 4728332,24 \\
\hline \multirow{6}{*}{ Cáceres } & \multirow{2}{*}{66070004} & \multirow{2}{*}{ Cáceres } & \multirow{2}{*}{ Paraguai } & \multirow{2}{*}{32400} & $-16,07611111$ & $-57,70222222$ \\
\hline & & & & & 8218390,62 & 4603906,41 \\
\hline & \multirow{2}{*}{66090000} & \multirow{2}{*}{ Descalvados } & \multirow{2}{*}{ Paraguai } & \multirow{2}{*}{47100} & $-16,73277778$ & $-57,74888889$ \\
\hline & & & & & 8145500,47 & 4600258,68 \\
\hline & \multirow{2}{*}{66120000} & \multirow{2}{*}{ Porto Conceição } & Paraguai & 0 & $-17,14333333$ & $-57,35944444$ \\
\hline & & & & 04000 & 8100741,23 & 4642557,61 \\
\hline
\end{tabular}

* Os valores superiores e inferiores correspondem, respectivamente, às coordenadas geográficas e métricas na projeção Policônica, para o Datum SIRGAS 2000.

Em seguida, foram consultadas as bases cartográficas da região para obter os arquivos com formato para dados geoespaciais em forma de vetor (ANA, 2020; IBGE, 2020). Finalmente, utilizando-se as informações da Tabela 1 e as referidas bases cartográficas foi elaborado o mapa da Figura 2, com auxílio do programa QGIS, versão 3.12 (QGIS DEVELOPMENT TEAM, 2020). Nessa Figura pode-se observar a distribuição dos postos fluviométricos na área de estudo, bem como a localização e extensão dos principais cursos d'água e seus tributários, que drenam a Microrregião do Alto Pantanal de Mato Grosso.

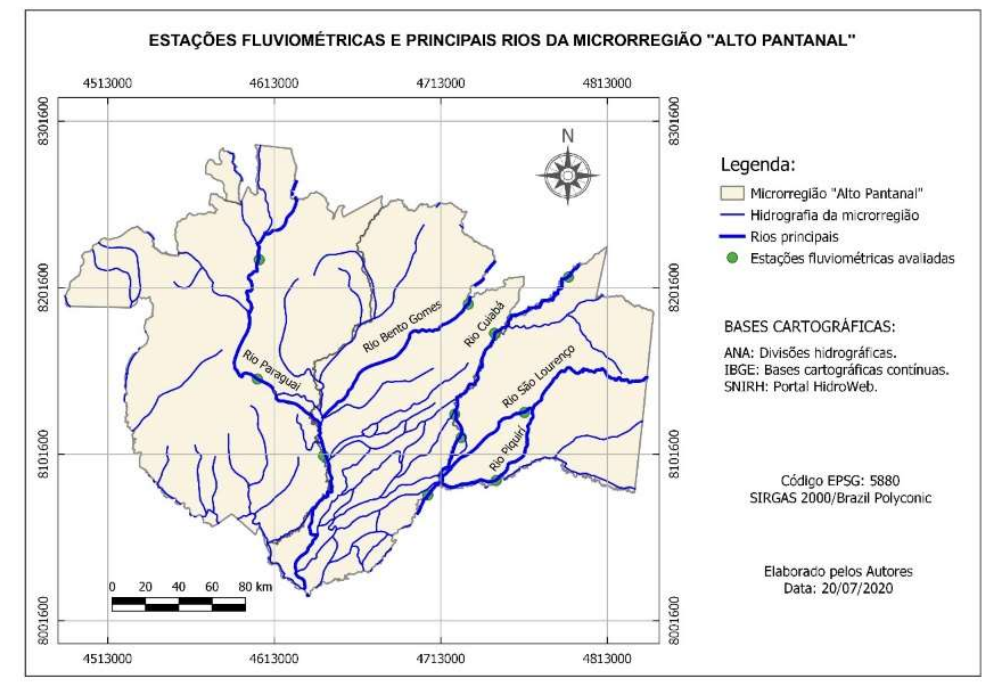

Figura 2: Estações fluviométricas e principais cursos d'água na Microrregião do Alto Pantanal - Mato Grosso, Brasil.

Na sequência, foram obtidos os dados de vazão diária para as 11 estações fluviométricas durante um período superior a 30 anos, variando entre os anos 1960 e 2019. Os valores de vazão foram armazenados em planilhas eletrônicas e organizados na forma de vetores colunas por meio de um subprograma, desenvolvido com o módulo VBA ('Visual Basic for Applications'), disponível na planilha Microsoft EXCEL. Além disso, o mencionado subprograma eliminou as células vazias, correspondentes aos dias sem leitura de vazão, visando evitar possíveis erros na análise e interpretação dos dados. Logo após, os valores foram classificados na 
ordem decrescente e foram calculadas as probabilidades ou frequências de ocorrência das respectivas vazões, bem como as suas principais estatísticas descritivas, com base nas medidas de posição e dispersão. Em seguida, elaboraram-se as curvas de permanência para cada posto fluviométrico. Esses procedimentos gráficos e analíticos foram realizados com o programa R (R CORE TEAM, 2020).

A vazão média possibilita caracterizar a capacidade hídrica de uma bacia hidrográfica e seu potencial energético. Essa variável hidrológica de longo período, constitui a maior vazão que pode ser regularizada em uma bacia (TUCCl et al., 2006). Contudo, devem ser considerados, além da média, outros valores de vazão de interesse para fins de análises estatística, como a vazão para 10\%, 25\%, 50\% (mediana), 75\%, 90\% e 95\% do tempo total da série histórica. Essas percentagens do tempo indicam a probabilidade ou frequência do total, em que os valores de vazão podem ser igualados ou superados. Assim, nesta pesquisa foram incluídos, em destaque, os pontos correspondentes às percentagens citadas anteriormente nas curvas de permanência.

Para complementar os estudos e facilitar a comparação entre bacias utilizou-se o conceito de vazão específica média. $O$ índice de vazão específica média é determinado pela razão entre a vazão média em uma dada seção de medição e a respectiva área de drenagem (TUCCI, 2002). Contudo, no presente estudo foram determinadas as vazões específicas diárias para as frequências ou probabilidades, ou seja, da percentagem do tempo de interesse estatístico, conforme a seguinte equação:

$$
q=\frac{1000 \cdot Q}{A}
$$

em que: q= Vazão específica diária para a dada frequência $\left(\mathrm{L} \mathrm{s}^{-1} \mathrm{~km}^{-2}\right)$; $\mathrm{Q}=$ Vazão diária para a dada frequência $\left(\mathrm{m}^{3} \mathrm{~s}^{-1}\right)$; $A=$ Área de influência ou drenagem $\left(\mathrm{km}^{2}\right)$.

\section{RESULTADOS E DISCUSSÃO}

As principais estatísticas descritivas para a série histórica de vazões diárias, registradas nas estações fluviométricas da microrregião do Alto Pantanal Mato-Grossense, Brasil, constam na Tabela 2. Na referida Tabela, pode-se observar que os valores das medidas de posição foram muito discrepantes, verificando-se uma diferença entre as médias e as medianas de 757,6843 e 711,1410 $\mathrm{m}^{3} \mathrm{~s}^{-1}$, respectivamente. Nota-se que, esses dois valores foram calculados para o município de Poconé, indicando que o Rio Bento Gomes apresenta graves problemas de vazão. A baixa vazão diária do Rio Bento Gomes pode estar relacionada com a sua menor área de drenagem, que por sua vez interfere na quantidade de água captada dos mananciais e chuvas. Outro aspecto importante pode ser a ação antrópica do homem, principalmente desmatamento e queimadas, que podem intensificar e acelerar o processo de assoreamento dos rios, causando redução na vazão e desvio dos cursos d'água, embora esse assunto não pertença ao escopo desta pesquisa.

Tabela 2: Estatísticas descritivas para a série histórica de vazões diárias nas estações fluviométricas estudadas.

\begin{tabular}{|c|c|c|c|c|c|c|c|c|}
\hline \multicolumn{2}{|c|}{ Dados da Estação } & \multicolumn{7}{|c|}{ Estatística descritiva } \\
\hline Município & Código & $\begin{array}{l}\text { Média } \\
\left(\mathrm{m}^{3} \mathrm{~s}^{-1}\right)\end{array}$ & $\begin{array}{l}\text { Mediana } \\
\left(\mathrm{m}^{3} \mathrm{~s}^{-1}\right)\end{array}$ & $\begin{array}{l}\text { Desvio } \\
\text { Padrão } \\
\left(\mathrm{m}^{3} \mathrm{~s}^{-1}\right)\end{array}$ & $\begin{array}{l}\text { Coeficiente } \\
\text { Variação (\%) }\end{array}$ & de & $\begin{array}{l}\text { Erro } \\
\text { Padrão } \\
\left(\mathrm{m}^{3} \mathrm{~s}^{-1}\right)\end{array}$ & $\begin{array}{l}\text { Intervalo de confiança } \\
\text { para } 95 \% \\
\left(\mathrm{~m}^{3} \mathrm{~s}^{-1}\right)\end{array}$ \\
\hline \multirow{3}{*}{$\begin{array}{l}\text { Barão } \\
\text { Melgaço }\end{array}$} & 66280000 & 415,2180 & 278,6490 & 319,0837 & 76,8473 & & 2,3607 & $\pm 4,6268$ \\
\hline & 66370000 & 376,1885 & 359,1400 & 171,9277 & 45,7025 & & 1,2837 & $\pm 2,5159$ \\
\hline & 66470000 & 266,0037 & 255,4210 & 93,5840 & 35,1814 & & 0,7324 & $\pm 1,4355$ \\
\hline
\end{tabular}




\begin{tabular}{|c|c|c|c|c|c|c|c|}
\hline & 66650000 & 301,7619 & 217,8760 & 193,7538 & 64,2075 & 1,5539 & $\pm 3,0455$ \\
\hline \multirow{4}{*}{ Poconé } & 66340000 & 364,4074 & 297,2830 & 205,6825 & 56,4430 & 1,5856 & $\pm 3,1077$ \\
\hline & 66360000 & 289,7230 & 289,6710 & 114,3968 & 39,4849 & 0,9015 & $\pm 1,7668$ \\
\hline & 66710000 & 777,4651 & 715,9800 & 277,3950 & 35,6794 & 3,0923 & $\pm 6,0608$ \\
\hline & 66110000 & 19,7808 & 4,8390 & 29,0096 & 146,6558 & 0,2376 & $\pm 0,4657$ \\
\hline \multirow{3}{*}{ Cáceres } & 66070004 & 538,6605 & 417,7510 & 322,2488 & 59,8224 & 2,3042 & $\pm 4,5162$ \\
\hline & 66090000 & 608,4595 & 537,6520 & 269,2202 & 44,2462 & 2,1144 & $\pm 4,1442$ \\
\hline & 66120000 & 412,9676 & 394,0300 & 136,9838 & 33,1706 & 1,1054 & $\pm 2,1665$ \\
\hline
\end{tabular}

De acordo com a Tabela 2, as medidas de dispersão evidenciaram elevada flutuação dos seus valores, principalmente, o desvio padrão com diferença de $293,2392 \mathrm{~m}^{3} \mathrm{~s}^{-1}$ entre as vazões nos postos fluviométricos 66070004 (Cáceres, Rio Paraguai) e 66110000 (Poconé, Rio Bento Gomes), bem como o coeficiente de variação com amplitude de 113,4852\%, correspondentes aos postos fluviométricos 66120000 e 66110000 . Os postos fluviométricos localizados nos Rios São Lourenço (66470000), Cuiabá (66360000 e 66710000) e Paraguai (66120000) apresentaram menor variabilidade de vazão, entretanto, o posto instalado no Rio Bento Gomes teve a maior, o que caracteriza susceptibilidade a eventos extremos como enchentes e estiagens. As particularidades desse curso d'água reduzem a probabilidade de estimar a vazão ao longo do ano com adequada precisão, confirmado estatisticamente pela estreita margem do intervalo de confiança para $95 \%$.

A baixa média de vazão diária e o elevado coeficiente de variação estimado para a estação Perto de Poconé (66110000) no rio Bento Gomes podem estar associados às atividades de mineração informal, sob a forma de garimpos, que resultam no precário controle ambiental e do ponto de vista dos impactos físicos, o beneficiamento de minério pode causar o assoreamento de drenagens (VEIGA et al., 1991; PEREIRA FILHO, 1995; BRASIL, 2006; CORINGA et al., 2016). Os valores do desvio padrão e do coeficiente de variação obtidos neste estudo foram superiores aos determinados por Andrade (2014), bem como por Rocha et al. (2018). Esses autores utilizaram séries anuais de vazões e ainda dividiram esse conjunto de dados em três períodos, o que reduz a sua variabilidade. Porém, na presente pesquisa foi realizada a análise das séries de vazões diárias registradas durante um período de no mínimo 30 anos, gerando como consequência uma elevada dispersão dos dados. O uso desses diferentes procedimentos estatísticos aplicados pode explicar as discrepâncias mencionadas anteriormente. Além disso, a área objeto de avaliação dos referidos autores correspondeu às bacias dos rios Aguapeí e Peixe, sendo muito menor, em relação à selecionada para esta investigação, que correspondeu a uma microrregião.

Na Figura 3 representam-se as curvas de permanência e vazões de referência correspondentes aos postos fluviométricos localizados no município Barão de Melgaço-MT. As estações Ilha Camargo (66370000) e São José do Boriréu (66470000) evidenciaram os melhores índices de uniformidade na vazão diária, dados pela menor amplitude correspondente à diferença entre as grandes e pequenas vazões e pela proximidade das vazões médias e medianas. Nota-se, ainda, que as vazões de referência para $95 \%$ do tempo $\left(Q_{95}\right)$ nesses postos fluviométricos foram superiores às estimadas nas estações Barão de Melgaço (66280000) e São José do Piquirí (66650000), as quais apresentaram elevada instabilidade nas vazões diárias. O regime de vazões diárias observado na estação Barão de Melgaço (66280000), caracterizado por fluxos de água muito diferentes ao longo do ano, pode estar associado às atividades antrópicas realizadas nesse trecho do Rio Cuiabá e seus tributários, pois a estação Ilha Camargo (66370000) está localizada nesse rio e mostrou uma 
permanência de vazão maior e mais estável.

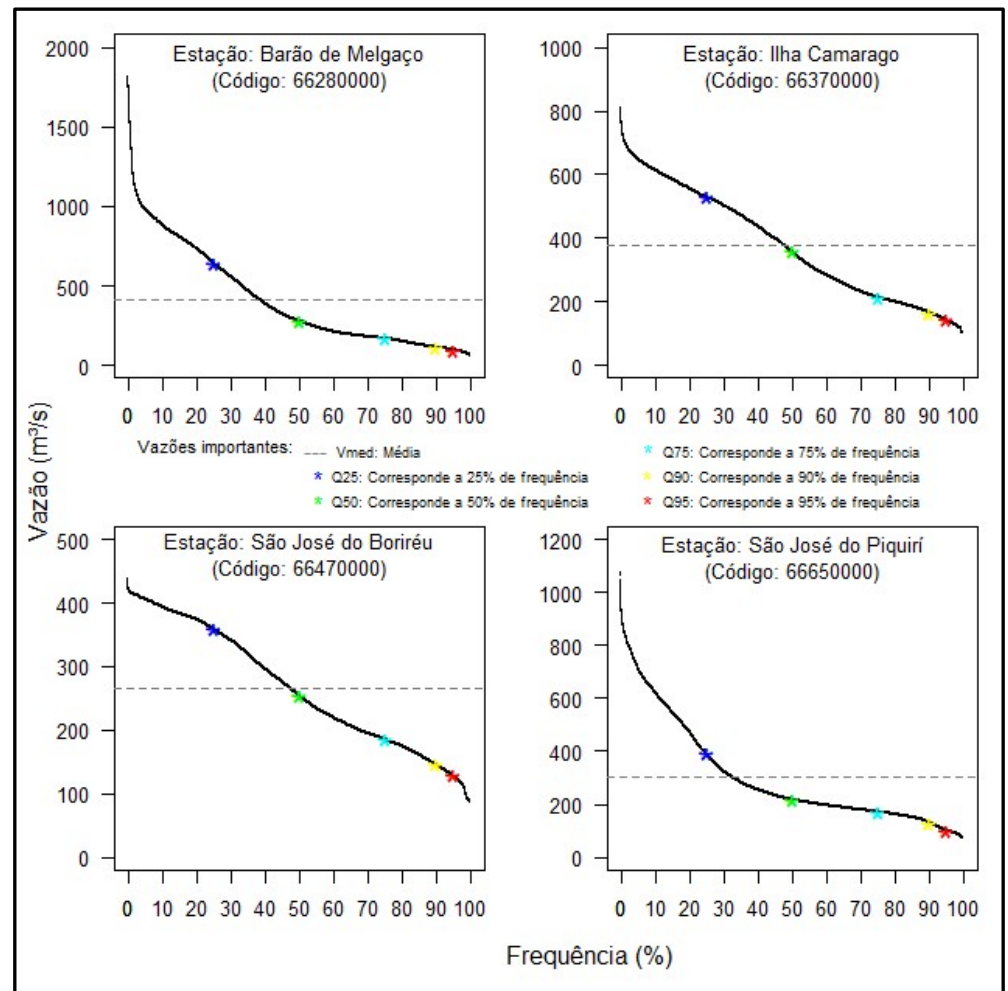

Figura 3: Curvas de permanência e vazões características para as estações fluviométricas localizadas no município de Barão de Melgaço-MT.

As curvas de permanência e vazões de referência para as quatro estações fluviométricas instalados no município Poconé-MT podem ser observadas na Figura 4. Nessa Figura constata-se que os três postos do Rio Cuiabá (66340000, 66360000 e 66710000) registraram maior vazão e estabilidade no fluxo de água. Não obstante, na estação Perto de Poconé (66110000) do Rio Bento Gomes foram coletadas vazões diárias muito baixas, sendo ao longo da série histórica inferiores a $35 \mathrm{~m}^{3} \mathrm{~s}^{-1}$ para mais de $50 \%$ do total de medições e a sua vazão de permanência para $95 \%$ do tempo $\left(Q_{95}\right)$ foi praticamente nula ou muito próxima de zero. Deve-se ressaltar, ainda, que a estação Pousada Taiamã (66710000) forneceu a curva de permanência com melhor desempenho no município de Poconé, pois $50 \%$ dos valores de vazão variaram de 530 a $1000 \mathrm{~m}^{3} \mathrm{~s}^{-1}$ e a vazão de permanência para $95 \%$ do tempo $\left(Q_{95}\right)$ foi em torno de $420 \mathrm{~m}^{3} \mathrm{~s}^{-1}$. Essas desigualdades entre as vazões ocorreram, provavelmente, devido às diferentes áreas de drenagem dos rios e às atividades antrópicas desenvolvidas na região.

As características da vazão diária para os três postos fluviométricos situados no Rio Paraguai podem ser observadas na Figura 5. Conforme essa Figura, as curvas de permanência apresentaram particularidades diferentes, em função das vazões de referência e da amplitude entre os pequenos e grandes valores do fluxo de água. Nesse sentido, os melhores indicadores de desempenho corresponderam à estação fluviométrica descalvados (66090000), pois 50\% dos valores de vazão diária oscilaram entre 392,0540 e $810,0600 \mathrm{~m}^{3} \mathrm{~s}^{-1} \mathrm{e}$ a sua vazão de referência para $95 \%$ do tempo $\left(Q_{95}\right)$ foi de $255,8330 \mathrm{~m}^{3} \mathrm{~s}^{-1}$, a maior estimada no Rio Paraguai para a microrregião em estudo. 


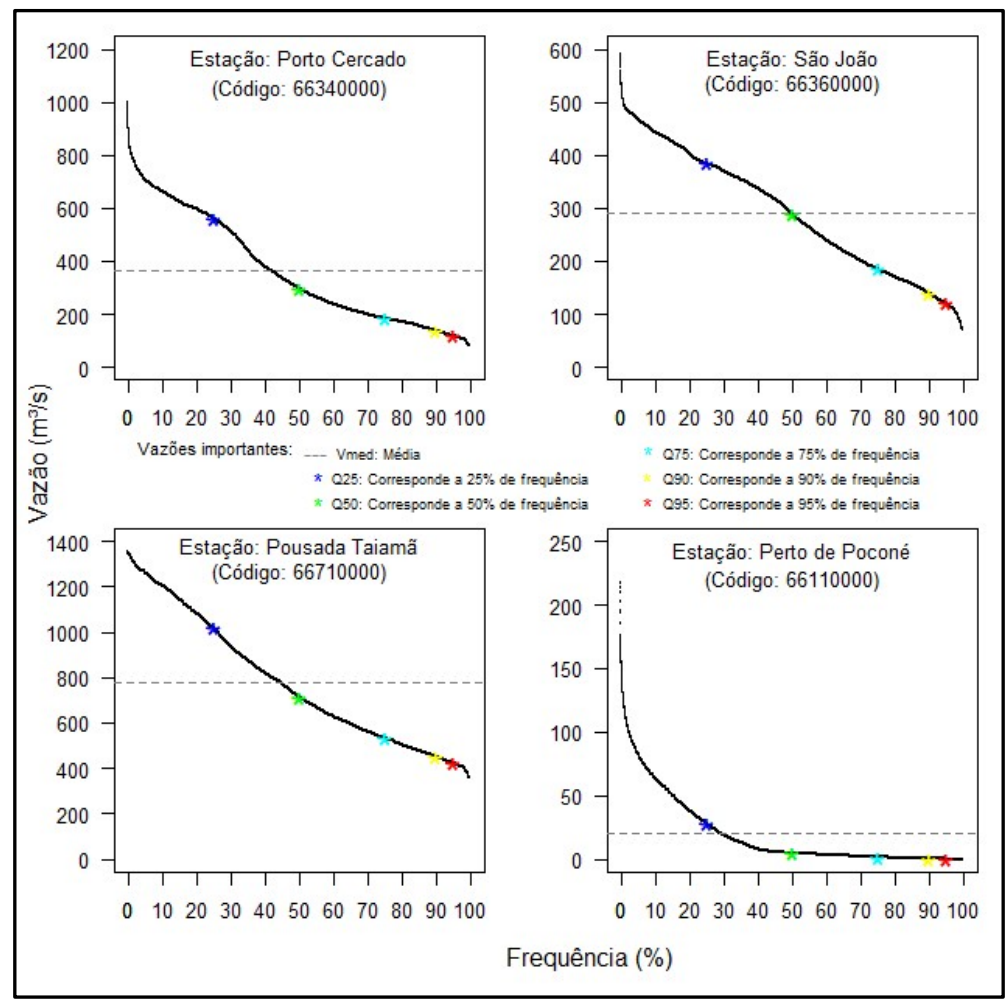

Figura 4: Curvas de permanência e vazões características para as estações fluviométricas localizadas no município de Poconé-MT.

Ao comparar os postos Cáceres (66070004) e Porto Conceição (66120000), este último evidenciou uma maior estabilidade de vazões diárias, dada pela menor amplitude entre os valores determinados para as frequências de referência de $25 \%$ e $75 \%$, cujo intervalo representa $50 \%$ do total das leituras. Além disso, na estação fluviométrica Porto Conceição (66120000) foi registrada uma vazão diária de permanência para $95 \%$ do tempo $\left(Q_{95}\right)$ de $216,5150 \mathrm{~m}^{3} \mathrm{~s}^{-1}$, aproximadamente $14 \%$ superior à calculada para a estação Cáceres (66070004). As discrepâncias constatadas podem estar associadas ao uso e ocupação do solo às margens do Rio Paraguai, o que poderia interferir na vegetação nativa da região e consequentemente na aceleração do processo de assoreamento dos rios.

Na Tabela 3 apresentam-se os valores de vazões médias e específicas por unidade de superfície igualados ou superados com frequências de interesse estatístico para as estações fluviométricas estudadas. As vazões estimadas nos postos José do Boriréu (66470000), Descalvados (66090000) apresentaram a melhor uniformidade, seguida da calculada no posto Cáceres (66070004), pois nesta última estação verificaram-se elevados valores de vazão durante as cheias. Contudo, nas três estações foram registradas vazões específicas de permanência para $95 \%$ do tempo $\left(q_{95}\right)$ superiores a $5 \mathrm{~L} \mathrm{~s}^{-1} \mathrm{~km}^{-2}$. No posto fluviométrico Pousada Taiamã (66710000) foi constatada adequada uniformidade na vazão, porém, o seu valor foi de 4,4433 $\mathrm{L} \mathrm{s}^{-1} \mathrm{~km}^{-2}$, inferior ao determinado nos outros três mencionados anteriormente. A maior heterogeneidade foi observada na estação fluviométrica Perto de Poconé (66110000), elevadas vazões com pouca frequência até o valor de vazão inferior a $0,5 \mathrm{~L} \mathrm{~s}^{-1} \mathrm{~km}^{-2}$ para $95 \%$ do tempo $\left(q_{95}\right)$, característica que indica propensão a enchentes durante as cheias e fluxo de água crítico ou muito baixo durante o período de estiagem. Nas outras estações foi verificada uma uniformidade intermediária, isto é, valores intermediários durante as cheias e a estiagem. 


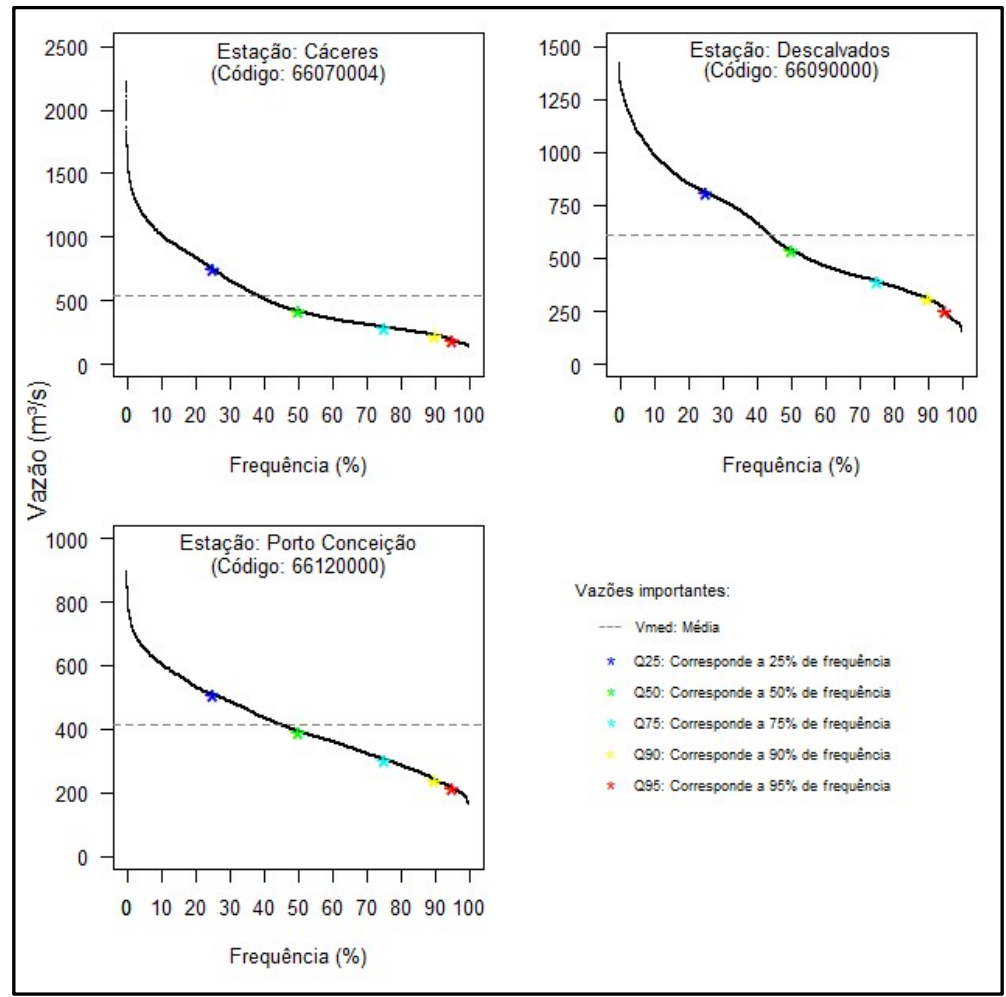

Figura 5: Curvas de permanência e vazões características para as estações fluviométricas localizadas no município de Cáceres-MT.

Tabela 3: Valores de vazões médias e específicas por unidade de superfície igualados ou superados com frequências de interesse estatístico para as estações fluviométricas estudadas.

\begin{tabular}{|c|c|c|c|c|c|c|c|c|c|}
\hline \multicolumn{2}{|l|}{ Dados da Estação } & \multicolumn{8}{|c|}{$\begin{array}{l}\text { Valores de vazão específica média para as frequências de interesse estatístico } \\
\left(\mathrm{L} \mathrm{s}^{-1} \mathrm{~km}^{-2}\right)\end{array}$} \\
\hline Município & Código & $\mathrm{q}_{5}$ & $\mathrm{q}_{10}$ & $\mathrm{q}_{25}$ & $q_{\text {média }}$ & $q_{50}$ & $\mathrm{q}_{75}$ & $\mathrm{q}_{90}$ & $q_{95}$ \\
\hline \multirow{4}{*}{ Barão de Melgaço } & 66280000 & 34,0179 & 30,5920 & 22,2782 & 14,3674 & 9,6418 & 5,8417 & 3,9461 & 3,3691 \\
\hline & 66370000 & 16,6781 & 15,7387 & 13,5865 & 9,6459 & 9,2087 & 5,5070 & 4,2702 & 3,6817 \\
\hline & 66470000 & 16,8590 & 16,3198 & 14,9416 & 11,0375 & 10,5984 & 7,7118 & 6,0622 & 5,3517 \\
\hline & 66650000 & 23,9348 & 20,7890 & 13,0341 & 10,0587 & 7,2625 & 5,7323 & 4,4037 & 3,3771 \\
\hline \multirow{4}{*}{ Poconé } & 66340000 & 19,2190 & 17,9527 & 15,2050 & 9,8755 & 8,0564 & 4,9850 & 3,7678 & 3,2181 \\
\hline & 66360000 & 12,1666 & 11,5489 & 9,9972 & 7,5253 & 7,5239 & 4,8188 & 3,6588 & 3,1369 \\
\hline & 66710000 & 13,2798 & 12,6476 & 10,7018 & 8,1666 & 7,5208 & 5,5965 & 4,7620 & 4,4433 \\
\hline & 66110000 & 28,6488 & 22,1660 & 9,7405 & 6,7975 & 1,6629 & 0,5842 & 0,1756 & 0,0467 \\
\hline \multirow{3}{*}{ Cáceres } & 66070004 & 36,0581 & 31,3998 & 23,1517 & 16,6253 & 12,8935 & 8,9769 & 7,0738 & 5,8573 \\
\hline & 66090000 & 23,3305 & 21,0017 & 17,1987 & 12,9185 & 11,4151 & 8,3239 & 6,5848 & 5,4317 \\
\hline & 66120000 & 10,2422 & 9,4907 & 7,9633 & 6,4526 & 6,1567 & 4,7768 & 3,7661 & 3,3830 \\
\hline
\end{tabular}

Legenda: $q_{5}, q_{10}, q_{25}, q_{50}, q_{75}, q_{90}$ e q95 significam a frequência em que a vazão específica foi igualada ou superada.

Os valores de vazão específica média determinados para os postos fluviométricos Barão de Melgaço (66280000), Ilha Camargo (66370000), Porto Cercado (66340000), São João (66360000) e Pousada Taiamã (66710000), localizados no rio Cuiabá, foram inferiores aos estimados pelo Programa das Nações Unidas para o Desenvolvimento, no intervalo entre 17,9 e 20,5 $\mathrm{L} \mathrm{s}^{-1} \mathrm{~km}^{-2}$ (PNUD, 1995). Entretanto, conforme a referida fonte, para o rio São Lourenço a situação foi mais favorável, pois a sua vazão específica medida na estação São José do Boriréu (66470000) permaneceu entre os limites de 9,2 a 17,3 $\mathrm{L} \mathrm{s}^{-1} \mathrm{~km}^{-2}$ (Tabela 3). Segundo essa mesma referência bibliográfica, a vazão específica média do rio Paraguai variou de 11,7 a 16,3 L s $\mathrm{km}^{-2}$. Logo, os resultados deste estudo evidenciaram elevada variabilidade da vazão específica ao longo do rio Paraguai, dado que cada posto fluviométrico registrou valores diferentes em relação à essa faixa de vazões, ficando acima, dentro e abaixo, respectivamente, Cáceres (66070004), Descalvados (66090000) e Porto Conceição 
(66120000). Ressalta-se, ainda, que a vazão específica média dessa última estação foi bem menor que o limite inferior do citado intervalo.

Com base na Tabela 3, constata-se que a disponibilidade hídrica da microrregião do Alto Pantanal Mato-grossense foi baixa, inclusive, os valores médios de vazão específica registrados em todas as estações fluviométricas foram muito inferiores à média nacional de $21 \mathrm{~L} \mathrm{~s}^{-1} \mathrm{~km}^{-2}$, de acordo com dados da Secretaria de Recursos Hídricos do Ministério do Meio Ambiente (BRASIL, 2006). Essa microrregião caracteriza-se pelas consideráveis perdas de água por evapotranspiração devido à presença de grandes superfícies úmidas e alagadas, associadas a elevadas temperaturas, o que favorece essa evaporação e a redução do escoamento superficial dos cursos de água. Além disso, em décadas passadas a região foi cenário de intensa extração de metais com elevado valor econômico, principalmente ouro, sem o devido planejamento e de forma precária, trazendo como consequências a contaminação dos cursos d'água e assoreamento dos rios. A piscicultura na microrregião apresenta-se como uma alternativa incipiente para o seu desenvolvimento econômico, porém, referente ao meio ambiente, requerem-se melhorias na infraestrutura das demais atividades relacionadas (CURVO et al., 2020).

A presença de metais pesados em trechos do rio Bento Gomes foi corroborada pelos resultados sobre a qualidade de suas águas, devido à influência de ações antrópicas como a mineração, o desmatamento, a pecuária e o uso de fertilizantes (GIUSMIN, 2016). Isso concorda com os resultados da presente pesquisa, pois precisamente o posto fluviométrico Perto de Poconé (66110000) registrou as menores vazões médias e específicas da microrregião estudada. Deve-se ressaltar, ainda, que a bacia do rio Paraguai, principalmente no município de Poconé, apresenta elevado potencial de contaminação do sedimento e biota aquática da planície do Pantanal (VIEIRA et al., 2004). Além disso, essa contaminação pode causar assoreamentos de drenagens (PEREIRA FILHO, 1995).

No referido município são desenvolvidas outras atividades econômicas, como a pesca profissionalartesanal, amadora e de subsistência, o turismo de pesca associado à pesca amadora e formas de turismo relacionados com a natureza (TOCANTINS et al., 2011). Recentemente, na região do Pantanal Matogrossense, em especial nas proximidades do município de Poconé, as queimadas têm aumentado consideravelmente, o que interfere na quantidade e qualidade dos recursos hídricos, pois a destruição da vegetação nativa ou mata ciliar reduz a interceptação das chuvas e pela sua vez aumenta a erosão pluvial dos solos ocasionada pelo escoamento superficial com a retirada de material da cobertura do solo.

\section{CONCLUSÕES}

As curvas de permanência elaboradas nesta pesquisa foram precisas e confiáveis para avaliar a disponibilidade hídrica dos principais rios na microrregião do Alto Pantanal Mato-grossense, bem como estimar a vazão, em função da frequência de duração.

Ao longo da série histórica analisada, as estações que apresentaram a maior e a menor vazão de permanência foram, respectivamente, a Pousada Taiamã (Rio Cuiabá) e Perto de Poconé (Rio Bento Gomes), ressaltando-se que a disponibilidade hídrica mais estável foi observada na estação Pousada Taiamã. 
A metodologia aplicada apresentou-se como uma ferramenta adequada para verificar os limites de vazão diária e diagnosticar o estado dos cursos d'água na região, auxiliando no planejamento e distribuição racional dos recursos hídricos.

AGRADECIMENTOS: Ao Instituto Nacional de Meteorologia (INMET), à Agência Nacional de Águas (ANA) e ao Sistema Nacional de Informações sobre Recursos Hídricos (SNIRH), portal HidroWeb por possibilitar a consulta dos dados fluviométricos. De igual forma os autores agradecem ao Instituto Brasileiro de Geografia e Estatística (IBGE) pela permissão às bases cartográficas.

\section{REFERÊNCIAS}

ALHO, C. J. R.. Biodiversidade do Pantanal: sua magnitude, ocupação humana, ameaças ambientais e desafios para a conservação. Brazilian Journal of Biology, São Carlos, v.71, n.1, p.229-232, 2011. DOI: https://doi.org/10.1590/S1519$\underline{69842011000200001}$

ALVARES, C. A.; STAPE, J. L.; SENTELHAS, P. C.; GONÇALVES, J. L. M.; SPAROVEK, G.. Köppen's climate classification map for Brazil. Meteorologische Zeitschrift, Stuttgart, v.22, n.6, p.711-728, 2013. DOI: http://dx.doi.org/10.1127/0941$\underline{2948 / 2013 / 0507}$

ANA. Agência Nacional de Águas e Saneamento Básico. Rede Hidrometeorológica Nacional: Divisões Hidrográficas. Brasília: ANA, 2020.

ANDRADE, L. F.. Análise espaço-temporal do escoamento fluvial nas bacias hidrográficas dos rios Aguapeí e Peixe, Oeste Paulista, Brasil. Dissertação (Mestrado em Geografia) - Universidade Estadual Paulista, Presidente Prudente, 2014

BELLETTINI, A. L.. Análise da curva de permanência diária e mensal para a bacia do Rio Tubarão, SC. Monografia (Bacharelado em Engenharia de Energia) - Universidade Federal de Santa Catarina, Araranguá, 2019.

BRASIL. Ministério do Meio Ambiente. Secretaria de Recursos Hídricos. Caderno da Região Hidrográfica do Paraguai. Brasília: MMA, 2006.

CALMON, A. P. S.; SOUZA, J. C.; REIS, J. A. T.; MENDONÇA, A. S. F.. Uso combinado de curvas de permanência de qualidade e modelagem da autodepuração como ferramenta para suporte ao processo de enquadramento de cursos d'água superficiais. Revista Brasileira de Recursos Hídricos, Porto Alegre, v.21, n.1, p.118-133,2016. DOI: http://dx.doi.org/10.21168/rbrh.v21n1.p118-133

CORINGA, J. E. S.; PEZZA, L.; CORINGA, E. A. O.; WEBER, O. L. S.. Distribuição geoquímica e biodisponibilidade de metais traço em sedimentos no Rio Bento Gomes, Poconé - MT, Brasil. Acta Amazônica, Manaus, v.46, n.2, p.161-174, 2016. DOI: http://dx.doi.org/10.1590/1809-4392201502215

COSTA, A. S.; CARIELLO, B. L.; BLANCO, C. J. C.; PESSOA, F. C. L.. Regionalização de curvas de permanência de vazão de regiões hidrográficas do estado do Pará. Revista Brasileira de Meteorologia, São José dos Campos, v.27, n.4, p.413 422, 2012. DOI: http://dx.doi.org/10.1590/S0102-

\section{$\underline{77862012000400005}$}

CRUZ, J. C.; TUCCI, C. E. M.. Estimativa da disponibilidade hídrica através da curva de permanência. Revista Brasileira de Recursos Hídricos, Porto Alegre, v.13, n.1, p.111124,2008. DOI: http://dx.doi.org/10.21168/rbrh.v13n1.p111-124

CURVO, L. R. V.; FERREIRA, M. W.; PORFIRIO, G. E. O.; OLIVEIRA, M. A. C.; ALENCAR, S. B. A.; COSTA, C. S.; ANDRADE, G. B.. Avaliação da piscicultura na microrregião do Alto Pantanal - Mato Grosso, Brasil. Scientia Plena, Sergipe, v.16, n.1, p.1-16, 2020. DOI: https://doi.org/10.14808/sci.plena.2020.017401

FANTIN-CRUZ, I.; LOVERDE-OLIVEIRA, S.; GIRARD, P.. Caracterização morfométrica e suas implicações na limnologia de lagoas do Pantanal Norte. Acta Scientiarum Biological Sciences, Maringá, v.30, n.2, p.133-140, 2008. DOI: https://doi.org/10.4025/actascibiolsci.v30i2.3628

FERREIRA, A. B. B.. Pantanal Mato-Grossense: considerações sobre a proteção constitucional para um desenvolvimento econômico sustentável. INTERAÇõES, Campo Grande, v.14, n.1, p.11-20, 2013.

GIUSMIN, G.. Avaliação da disponibilidade de metais em água do Rio Bento Gomes no Pantanal de Poconé - MT. Monografia (Bacharelado em Gestão Ambiental) - Instituto Federal de Educação, Ciência e Tecnologia de Mato Grosso, Cuiabá, 2016.

GONÇALVES, H. C.; MERCANTE, M. A.; SANTOS, E. T.. Hydrological cycle. Brazilian Journal of Biology, São Carlos, v.71, n.1, p.241-253, 2011. DOI: https://doi.org/10.1590/S1519-69842011000200003

IBGE. Instituto Brasileiro de Geografia e Estatistica. Bases Cartográficas Contínuas. Rio de Janeiro: IBGE, 2020.

INMET. Instituto Nacional de Meteorologia. BDMEP: Banco de Dados Meteorológicos para Ensino e Pesquisa. Brasília: INMET, 2020.

JUNK, W. J.; CUNHA, C. N.. Pantanal: a large South American wetland at a crossroads. Ecological Engineering, Amsterdã, v.24, n.4, p.391-401, 2005. DOI:

http://dx.doi.org/10.1016/j.ecoleng.2004.11.012 
JUNK, W. J.; SILVA, C. J.. O Conceito do pulso de Inundação e suas implicações para o pantanal de Mato Grosso. In: SIMPÓSIO SOBRE RECURSOS NATURAIS E SÓCIOECONÔMICOS DO PANTANAL - MANEJO E CONSERVAÇÃO, 2. Anais. Corumbá: EMBRAPA-PANTANAL, 1999.

MAJER, R. C.. Representação de curvas de permanência de vazões para bacias hidrográficas situadas no estado do Rio Grande do Sul. Monografia (Bacharelado em Engenharia Hídrica) - Universidade Federal de Pelotas, Pelotas, 2017.

NOVAIS, J. W. Z.; SANCHES, L.; SILVA, L. B. D.; MACHADO, N. G.; AQUINO, A. M.; PINTO JUNIOR, O. B.. Albedo do solo abaixo do dossel em área de Vochysia divergens Pohl no Norte do Pantanal. Revista Brasileira de Meteorologia, v.31, n.2, p.157-166, 2016. DOI: http://dx.doi.org/10.1590/0102$\underline{778631220150001}$

OLIVEIRA, L. L.; BARRETO, N. J. C.; JESUS, E. S.; CANANI, L. G. C.. Efeitos dos eventos extremos climáticos na variabilidade hidrológica em um rio de Ecossistema Tropical Amazônico. Revista Ibero Americana de Ciências Ambientais, v.11, n.4, p.145-153, 2020. DOI: http://doi.org/10.6008/CBPC2179$\underline{6858.2020 .004 .0013}$

PARANHOS FILHO, A. C.; MOREIRA, E. S.; OLIVEIRA, A. K. M.; PAGOTTO, T. C. S.; MIOTO, C. L.. Análise da variação da cobertura do solo no Pantanal de 2003 a 2010 através de sensoriamento remoto. Revista Engenharia Sanitária e Ambiental, Rio de Janeiro, v.19, p.19:69-76, 2014. DOI: http://dx.doi.org/10.1590/S1413-41522014019010000305

PEEL, M. C.; FINLAYSON, B. L.; MCMAHON, T. A.. Updated world of the Köppen-Geiger climate classification. Hydrology and Earth System Sciences, Göttingen, v.11, n.5, p.16331644, 2007. DOI: https://doi.org/10.5194/hess-11-1633$\underline{2007}$

PEREIRA FILHO, S. R.. Metais pesados nas sub-bacias hidrográficas de Poconé e Alta Floresta. Rio de Janeiro: CETEM/CNPq, 1995.

PINHEIRO, A.; BADIA, S. B.. Efeitos da curva-chave sobre a curva de permanência dos escoamentos em uma bacia agrícola. Revista de Estudos Ambientais, Blumenau, v.10, n.2, p.64-70, 2008. DOI: http://dx.doi.org/10.7867/1983$\underline{1501.2008 v 10 n 2 p 64-70}$

PNUD. Programa das Nações Unidas para o Desenvolvimento. Caracterização Hidrográfica do Estado de Mato Grosso: Bacias Amazônica, Araguaia, Tocantina e Platina. Cuiabá: PNUD, 1995.

PRUSKI, F. F.; RODRIGUEZ, R. G.; SOUZA, J. F.; SILVA, B. M. B.; SARAIVA, I. S.. Conhecimento da disponibilidade hídrica natural para a gestão dos recursos hídricos. Revista de Engenharia Agrícola, Jaboticabal, v.31, n.1, p.67-77, 2011.
DOI: http://dx.doi.org/10.1590/S0100-69162011000100007

QGIS DEVELOPMENT TEAM. QGIS Geographic Information System. Open-Source Geospatial Foundation Project. Versão 3.12.0-București. 2020.

R CORE TEAM. R: A language and environment for statistical computing. Viena: R Foundation for Statistical Computing, 2020.

ROCHA, P. C.; SANTOS, A. A.. Análise hidrológica em bacias hidrográficas. Mercator, Fortaleza, v.17, n.e17025, p.1-18, 2018. DOI: https://doi.org/10.4215/rm2018.e17025

ROLIM, P. A. M.; QUEIROZ, J. C. B.; JESUS, E. S.; OLIVEIRA, L. L.. Uso da modelagem hidrológica para calibração de curvachave de vazão em Rio Amazônico com efeito de remanso. Revista Ibero Americana de Ciências Ambientais, v.11, n.5, p.273-283, 2020. DOI: http://doi.org/10.6008/CBPC2179$\underline{6858.2020 .005 .0026}$

SILVA, C. J.. Ecological basis for the management of the Pantanal-Upper Paraguay River basin. In: SMITS, A. J. M.; NIENHUIS, P. H.; LEUVEN R. S. E. W.. New Approaches to River Management. Leiden: Bachuys Publishers, 2000. p.97117.

SILVA, C. J.; GIRARD P.. New challenges in the management of the Brazilian Pantanal and catchment area. Wetlands Ecology and Management, Switzerland, v.12, n.6, p.553-561, 2004. DOI: https://doi.org/10.1007/s11273-005-1755-0

TOCANTINS, N.; ROSSETTO, O. C.; BORGES, F. R.. Abordagem socioeconômica dos pescadores filiados à colônia Z11: Município de Poconé, Pantanal de Mato Grosso, Brasil. Revista Geográfica de América Central, San José, p.9, 2011.

TUCCI, C. E. M.. Hidrologia: ciência e aplicação. 3 ed. Porto Alegre: UFRGS, 2002.

TUCCI, C. E. M.; MENDES, C. A.. Avaliação Ambiental Integrada de Bacia Hidrográfica. 2 ed. Brasília: MMA, 2006.

VEIGA, M. M.; FERNANDES, F. R. C.; FARID, L. H.; MACHADO, J. E. B.; SILVA, A. O.; LACERDA, L. D.; SILVA, A. P.; SILVA, E. C.; MARINS, R. V.; IMBASSAHY, J. A.; PFEIFFER, W. C.; BASTOS, W. R.; SOUZA, V. P.. Poconé: Um campo de estudos do impacto ambiental do garimpo. Rio de Janeiro: CETEM/CNPq, 1991.

VIEIRA, L. M.; SILVA, V. N.; CAMPOS, R. C.. Níveis de mercúrio total na carne de peixes como indicadores de contaminação em sistemas aquáticos no Pantanal. In: SIMPÓSIO SOBRE RECURSOS NATURAIS E SOCIOECONÔMICOS DO PANTANAL, 4. Anais. Corumbá: EMBRAPA-PANTANAL, 2004.

A CBPC - Companhia Brasileira de Produção Científica (CNPJ: 11.221.422/0001-03) detém os direitos materiais desta publicação. Os direitos referem-se à publicação do trabalho em qualquer parte do mundo, incluindo os direitos às renovações, expansões e disseminações da contribuição, bem como outros direitos subsidiários. Todos os trabalhos publicados eletronicamente poderão posteriormente ser publicados em coletâneas impressas sob coordenação da Sustenere Publishing, da Companhia Brasileira de Produção Científica e seus parceiros autorizados. Os (as) autores (as) preservam os direitos autorais, mas não têm permissão para a publicação da contribuição em outro meio, impresso ou digital, em português ou em tradução. 